\title{
THE EFFECT OF SWALLOWING ANXIETY ON GASTROSCOPY TIME AND SEDATION TYPE AND ITS RELATIONSHIP WITH HEALTH LITERACY
}

\author{
Feriste SAKAR ${ }^{1}$, Hakan DEMIRCI ${ }^{2}$
}

${ }^{1}$ Ulubatli Hasan Family Health Center, Bursa, TURKEY

2 Department of Family Medicine, University of Health Sciences Turkey Bursa Yuksek Ihtisas Training and Research Hospital, Bursa, TURKEY

\section{ABSTRACT}

Aim: The aim of this study is to investigate the effect of swallowing anxiety on gastroscopy time and sedation type and its relationship with health literacy.

Methods: Participants between the ages of 18-75, who were registered in Karacabey Ulubatli Hasan Family Health Center and applied with dyspeptic complaints and underwent gastroscopy, were evaluated in the study. Persons who volunteered to participate in the study were examined through the Sociodemographic Data Form, the State Trait Anxiety Inventory (STAI), the Swallowing Anxiety Scale (SAS), and the Health Literacy Scale (HL-EU-Q16).

Results: In the study, it was found that women's STAI and SAS mean scores were higher than men's mean scores $(p<0.05)$. It was found that SAS scores differed significantly according to economic status $(p<0.05)$. It was determined that the rate of patients with undergraduate education was higher in the local anesthesia group $(p<0.05)$. It was found that the endoscopy period was longer in the patient group with psychiatric disease than in the group without psychiatric disease $(p<0.05)$. In the study, it was found that there was a significant positive correlation $(r=0.22, p=0.002)$ between SAS scores and STAI-I scores. It was found that there was a significant positive correlation $(r=0.37, p<0.001)$ between SAS scores and STAI-II scores. According to the STAI-I and STAI-II scales, as a result of the ROC analysis in order to predict the presence of anxiety in the patient and whether this anxiety is continuous; It is predicted that if the total score to be obtained from SAS is $>19$, the patient may have anxiety, and if the total score is $>22$, the continuity of this anxiety can be mentioned. In addition, a statistically significant negative correlation was found between the ages of the cases and their HL-EU-Q16 scores $(r=-0.14, p=0.05)$.

Conclusions: State and trait anxiety symptoms and swallowing anxiety symptoms are common in patients presenting with dyspeptic complaints. In dyspeptic patients, SAS is an appropriate measurement tool in order to determine swallowing problems of psychological origin. It may be beneficial for their mental health to provide anti-anxiety information before endoscopy to people with a score of 19 or higher on SAS. The fact that health literacy results are not associated with anxiety tests is a valuable finding. It suggests that while making the accurate health decisions, individuals exhibit an anxiety-free behavior.

Keywords: Dyspepsia, swallowing anxiety, state and trait anxiety, health literacy

Corresponding Author: Feriste SAKAR feriste.sakar@saglik.gov.tr

Received: December 30, 2021; Accepted: December 30, 2021; Published Online: December 31, 2021

Cite this article as: Sakar, F. \& Demirci, H. (2021). The Effect of Swallowing Anxiety on Gastroscopy Time and Sedation Type and Its Relationship with Health Literacy 1(3), 108-121. 



\section{Introduction}

Dyspepsia is a digestive disorder known as indigestion; symptoms manifest as upper abdominal fullness, heartburn, nausea, belching or upper abdominal pain (1). According to studies in the literature, the prevalence of dyspepsia is between $17 \%$ and $57 \%$; Dyspepsia was found to be more common in women, smokers, users of nonsteroidal anti-inflammatory drugs, and Helicobacter pylori positive individuals. It has been evaluated that there may be great differences in symptoms in these groups $(2,3)$.

It has been evaluated that organic causes of dyspepsia are peptic ulcer, gastroesophageal reflux disease, gastric or esophageal cancer, pancreatic or biliary diseases, intolerance to food or drugs, and other infectious or systemic diseases (4). In addition, there is no definite underlying cause in dyspepsia of psychological origin. Delayed gastric emptying, impaired adaptation of the stomach to food, hypersensitivity to gastric distension, altered duodenal sensitivity to lipids or acids, suppression of gastric electrical rhythm in the proximal stomach, and changes in the autonomic nervous system are the causes that have been evaluated.

It has been found that personality and psychiatric disorders are more common in dyspeptic patients with severe complaints, and the severity of dyspeptic symptoms in patients older than 18 years is associated with the presence of depression, somatization symptoms, coping strategies, and age (5). Acute or longer-lasting psychosocial stressors often precede the onset and exacerbation of functional dyspepsia (FD) symptoms. It has been evaluated that depressed mood and deterioration in quality of life are common in patients suffering from functional dyspepsia (6).

It has been found that health-related anxiety is common in dyspeptic patients referred for endoscopy, and the results of endoscopy reduce mental problems such as preoccupation with health, fear of illness and death in patients with severe anxiety, and the effects of this situation continue for 6 months (7). It was found that the waiting time did not have a significant effect on the perception of pain and discomfort associated with the endoscopic procedure, while high anxiety levels before the procedure decreased the tolerance in endoscopy (8). In another study, it was stated that the use of sedation may be more beneficial in order to perform the endoscopy without complications in people who show high anxiety before endoscopy (9).

Swallowing problems have been studied under different titles in the literature, such as dysphagia, odynophagia, globus hysterecus, swallowing phobia, and swallowing anxiety. Dysphagia is dysphagia and is considered as a health problem that can be seen on its own in addition to a health problem that accompanies other diseases (10). Odynophagia is the feeling of pain during swallowing. Globus hysteresis is defined as a mental-origin converse symptom accompanied by a sensation of a lump in the throat (esophagus or airway) or a foreign object in connection with swallowing, and phagophobia is defined as swallowing phobia (11-13) . In addition, swallowing anxiety is a concept that has just begun to be studied in the literature, and it is a concept that was originally put forward to evaluate psychological-based swallowing difficulties (14).

The incidence of air swallowing in patients with functional dyspepsia was found to be significantly higher when compared to controls, and dysphagia may be an important symptom in patients with dyspepsia, whereas studies in the literature focused only on general anxiety symptoms as a psychogenic factor in endoscopic applications in patients with dyspepsia (9, 15- 18. Therefore, in this study, the effect of 
swallowing anxiety on endoscopy results was investigated in patients presenting with dyspepsia symptoms.

\section{Methods}

The study was carried out between October 2019 and March 2020, and participants aged 18-75 years who were registered to Karacabey Ulubatlı Hasan FHC and applied with dyspeptic complaints were included in the study. In the study, the connection between gastroscopy results, swallowing anxiety, anxiety and health literacy of dyspeptic patients was carried out in a descriptive-observational and relationship-seeking research design. Inclusion criteria for the study were volunteering to participate in the study, being between the ages of 18-75, being a registered patient in Karacabey Ulubatlı Hasan ASM, having an endoscopy planned for the patient due to dyspeptic complaints, and being at least literate. Exclusion criteria from the study were illiteracy, an emergency medical condition requiring hospitalization or intensive care, and female participants being pregnant.

In the study, information such as whether to perform gastroscopy, duration of gastroscopy, quality of gastroscopy, and duration of sedation were recorded by the researchers with the support of a specialist in the field. In the study, the data of the cases who gave up on endoscopy and whose endoscopy procedure could not be completed were excluded from the study from the beginning. As a result, the gastroscopy results of a total of 196 cases, 101 of whom were administered local anesthesia and 95 were anesthetized, were evaluated in this study, who were literate, aged 18-75, and volunteered to participate in the study.

\section{Evaluation Tools}

Sociodemographic Data Form: includes data related to age, gender, educational status, marital status and information about gastroscopy.

State-Trait Anxiety Inventory: It consists of two subdimensions, State Anxiety Inventory (STAI-I) and Trait Anxiety Inventory (STAI-II). The state anxiety scale consists of 20 questions measuring how an individual feels at a certain moment and under certain conditions (19). Items in the two scales are scored between 1 and 4 points, and high scores on the scales indicate increased anxiety.

Swallowing Anxiety Scale: It was developed to measure swallowing anxiety based on 119 panic disorder patients who were evaluated as having no organic problems. SAS consists of 10 questions. A high score on the SAS indicates that swallowing anxiety symptoms increase in individuals. The scale was developed in Turkish, and the Cronbach's alpha value of SAS was calculated as 0.89 (14).

Health Literacy Scale: HLS-EU is a measurement tool that consists of 16 questions and includes three subareas: "Healthcare", "Prevention from Disease", "Health Promotion", and evaluates health literacy. The standardized index score is used to calculate the total score $($ Index $=($ mean- 1$) *(50 / 3))$. The index score ranges from 0 to 50 . As the score obtained from the scale increases, the $\mathrm{HL}$ level also increases. The Turkish adaptation of the scale was made by Emiral et al. (2018), and it was found that the Cronbach alpha values of the subscales of the scale were 0.89 and their Cronbach alpha values were 0.70 and above (21).

\section{Statistical analysis}

The conformity of continuous variables to the normal distribution was examined using the Shapiro-Wilk test. Continuous variables using mean \pm standard deviation or median (minimum: maximum) values; categorical 
variables were expressed as $\mathrm{n}(\%)$. According to the normality test results, Mann Whitney $U$ test and Independent double sample $t$ test, ANOVA and Kruskal Wallis tests were used for comparisons between groups. Categorical variables were analyzed using the Chi-square test. Relationships between age and endoscopy time, State Anxiety Scale, Trait Anxiety Scale, Swallowing Anxiety Scale and HL-EU-Q16 scale were analyzed by correlation analysis and Spearman correlation coefficient was calculated. Logistic regression analysis was performed to investigate the factors that may have an effect on the patients' sleep. The internal consistency of the STAI-I, STAI-II, SAS and HL-EU-Q16 scales were analyzed using the Cronbach's alpha reliability coefficient. In order to predict the presence of anxiety in the patient and the persistence of this anxiety according to the STAI-I and STAI-II scales, the cutoff point value was determined for the Swallowing Anxiety Scale using ROC (Receiver operator characteristic curve) analysis. SPSS (IBM Corp. Released 2012. IBM SPSS Statistics for Windows, Version 21.0. Armonk, NY: IBM Corp.) program was used for statistical analysis, and type I error level was accepted as $5 \%$ in statistical analysis.

\section{Results}

The median age of the patients included in the study was 45.50 years (minimum:18-maximum:75). When analyzed according to gender distribution, it is seen that while the rate of women is $60.70 \%$, the rate of men is $39.30 \%$. $40.80 \%$ of the participants were housewives, $33.20 \%$ were workers, $14.30 \%$ were retired, $6.60 \%$ were students, and $5.10 \%$ were civil servants. When analyzed by education level, the rate of primary school graduates is $43.90 \%$, the rate of secondary school graduates is $14.30 \%$, the rate of those with high school level education is $24.50 \%$, the rate of those with undergraduate level education is $9.70 \%$ and the rate of those with an associate degree level is $24.50 \%$. the rate of those with an education level was determined as $7.70 \%$. When analyzed according to smoking, $50.50 \%$ of the patients included in the study stated that they smoke. As a result of the examination made in terms of marital status, it is seen that $76 \%$ of the participants are married and $24 \%$ are single.

When analyzed according to gender distribution, the median score of women from the state anxiety scale is 39 (minimum: 20-maximum: 73) and men's is 35 (minimum: 20-maximum: 62), and it has been determined that women's total score from the state anxiety scale is higher $(p=0.006)$. As a result of the analysis of trait anxiety scale according to gender, the average scale score of women is $45.23 \pm 8$ (minimum: 24-maximum: 64), while it is $42.61 \pm 7.02$ (minimum: 23-maximum: 60) in men. It was determined that the score obtained from the scale was higher $(p=0.020)$. When examined according to gender distribution, the median score of women obtained from SAS is 22 (minimum: 10-maximum: 45) and the median score of men is 8 (minimum: 10-maximum: 41), and it is seen that women's total scale score is higher $(p<0.001)$. It was determined that the SAS scores differed according to the economic situation $(p=0.015)$. In the subgroup analyzes carried out to determine the statuses showing the economic situation that caused the difference, it was seen that housewives had a higher SAS score than workers $(p=0.020)$. A significant inverse relationship was determined between age and the total score obtained from the HL-EU-Q16 scale ( $r s=-0.14$, $\mathrm{p}=0.050$ ) (Table 1). 
Table 1. The relationship between socio-demographic findings and STAI

\begin{tabular}{|c|c|c|c|c|}
\hline$n=196$ & STAI-I & STAI-I & SAS & HLS-EU-16 \\
\hline \multicolumn{5}{|l|}{ Age (years) } \\
\hline$r_{s}$ & -0.08 & 0.03 & -0.03 & -0.14 \\
\hline$p$-value & 0.273 & 0.694 & 0.666 & 0.050 \\
\hline \multicolumn{5}{|l|}{ Gender } \\
\hline Female $(n=119)$ & $39(20: 73)$ & $45.23 \pm 8$ & $22(10: 45)$ & $19.79(0: 35,42)$ \\
\hline Male $(n=77)$ & $35(20: 62)$ & $42.61 \pm 7,02$ & $18(10: 41)$ & 19.79(0:33,33) \\
\hline$p$-value & $0.006^{\mathrm{a}}$ & $0.020^{c}$ & $<0.001^{\mathrm{a}}$ & $0.496^{\mathrm{a}}$ \\
\hline \multicolumn{5}{|l|}{ Occupation } \\
\hline Student $(n=13)$ & $40(29: 53)$ & $45.69 \pm 8,78$ & $22(10: 34)$ & 19.79(12.50:32.29) \\
\hline Officer $(n=10)$ & $45(26: 58)$ & $44.90 \pm 7.03$ & $20.50(14: 44)$ & $20.31(12.50: 30.21)$ \\
\hline Worker $(n=65)$ & $36(20: 62)$ & $42.37 \pm 6.88$ & $18(10: 35)$ & $20.83(0: 33.33)$ \\
\hline Retired $(n=28)$ & $37.50(20: 62)$ & $43.61 \pm 7.73$ & $19(10: 27)$ & 18.75(11.46:33.33) \\
\hline Housewife $(n=80)$ & $37.50(20: 73)$ & $45.56 \pm 8.11$ & $23.50(10: 45)$ & 19.79(0:35.42) \\
\hline$p$-value & $0.520^{b}$ & $0.141^{d}$ & $0.015^{b}$ & $0.542^{b}$ \\
\hline \multicolumn{5}{|l|}{ Education } \\
\hline Primary $(n=86)$ & $36(20: 73)$ & $44.73 \pm 7.74$ & $20(10: 45)$ & 19.79(4.17:33.33) \\
\hline Secondary $(n=28)$ & $38(20: 58)$ & $44.64 \pm 8.30$ & $18(10: 35)$ & $21.35(0: 33.33)$ \\
\hline High School $(n=48)$ & $39(20: 62)$ & $43.14 \pm 7.03$ & $21.50(10: 44)$ & $19.27(0: 35.42)$ \\
\hline University (2 years) ( $n=15)$ & $38(25: 60)$ & $43.20 \pm 7.84$ & $19(12: 33)$ & 23.96(9.38:32.29) \\
\hline University (>2 years) $(n=19)$ & $37(27: 56)$ & $44.58 \pm 8.74$ & $22(10: 34)$ & $20.83(12.50: 32.29)$ \\
\hline$p$-value & $0.744^{b}$ & $0.795^{d}$ & $0.828^{b}$ & $0.568^{b}$ \\
\hline \multicolumn{5}{|l|}{ Smoking } \\
\hline Yes (n=99) & $37(20: 62)$ & $44.18 \pm 7.91$ & $20(10: 44)$ & 19.79(0:34.38) \\
\hline No $(n=97)$ & $37(20: 73)$ & $44.22 \pm 7.56$ & $21(10: 45)$ & 19.79(4.17:35.42) \\
\hline$p$-value & $0.816^{\mathrm{a}}$ & $0.975^{c}$ & $0.319^{a}$ & $0.521^{\mathrm{a}}$ \\
\hline \multicolumn{5}{|l|}{ Marital Status } \\
\hline Single $(n=47)$ & $35(20: 62)$ & $43.79 \pm 7,84$ & $20(10: 45)$ & $19.79(11,46: 32.29)$ \\
\hline Married ( $n=149)$ & $38(20: 73)$ & $44.33 \pm 7,70$ & $20(10: 45)$ & 19.79(0:35.42) \\
\hline$p$-value & $0.288^{a}$ & $0.676^{c}$ & $0.630^{\mathrm{a}}$ & $0.344^{\mathrm{a}}$ \\
\hline
\end{tabular}

Data are expressed as median (minimum: maximum) and mean $\pm s d$.deviation.

a: Mann Whitney $U$ test, b: Kruskal Wallis test, c: Independent two-sample t test, d: ANOVA test. rs: Spearman correlation coefficient, STAI-I: State anxiety inventory, STAI-II: Trait anxiety inventory

The median age was 46 years (minimum:18maximum:75) in the group of patients given local anesthesia and 45 years (minimum:18-maximum:75)

in the anesthetized patients, and there was no 
difference between the groups according to age $(p=0.858)$. Although there was no difference between the groups in terms of gender distribution $(p=0.064)$, it was observed that the rate of women was higher in both groups (54.50\%; 67.40\%). When analyzed according to the economic situation, there was no difference between the groups $(p=0.756)$. It was determined that there was a difference between the groups according to the education level $(p=0.036)$.
The distribution of patients in both groups according to education level is given in figure-2. In the subgroup analyzes carried out; While it was determined that the rate of patients with undergraduate education was higher in the local anesthesia group, it was determined that there was no difference between the medication groups according to the other levels of education level (Table 2).

Table 2. The relationship of anesthesia type with socio-demographic data and the scales used

\begin{tabular}{|c|c|c|c|}
\hline & $\begin{array}{l}\text { Local Anesthesia } \\
(n=101)\end{array}$ & $\begin{array}{l}\text { General Anesthesia } \\
(n=95)\end{array}$ & p-değeri \\
\hline Age (years) & $46(18: 75)$ & $45(18: 75)$ & $0.858^{\mathrm{a}}$ \\
\hline \multicolumn{4}{|l|}{ Gender } \\
\hline Female $(n=119)$ & $55(\% 54,50)$ & $64(\% 67,40)$ & \multirow{2}{*}{$0.064^{e}$} \\
\hline Male $(n=77)$ & $46(\% 45,50)$ & $31(\% 32,60)$ & \\
\hline \multicolumn{4}{|l|}{ Occupation } \\
\hline Student $(n=13)$ & $8(\% 7,90)$ & $5(\% 5,30)$ & \multirow{5}{*}{$0.756^{\mathrm{e}}$} \\
\hline Officer $(n=10)$ & $6(\% 5,90)$ & $4(\% 4,20)$ & \\
\hline Worker $(n=65)$ & $35(\% 34,70)$ & $30(\% 31.60)$ & \\
\hline Retired $(n=28)$ & $15(\% 14,90)$ & $13(\% 13.70)$ & \\
\hline Housewife $(n=80)$ & $37(\% 36,60)$ & $43(\% 45.30)$ & \\
\hline \multicolumn{4}{|l|}{ Education } \\
\hline Primary $(n=86)$ & $45(\% 44,60)$ & $41(\% 43.20)$ & \multirow{5}{*}{$0.036^{\mathrm{e}}$} \\
\hline Secondary $(n=28)$ & $12(11,90)$ & $16(\% 16.80)$ & \\
\hline High School $(n=48)$ & $21(\% 20,80)$ & $27(\% 28.40)$ & \\
\hline University (2 years) ( $n=15)$ & $7(\% 6,90)$ & $8(\% 8.40)$ & \\
\hline University (>2 years) $(n=19)$ & $16(\% 15,80)$ & $3(\% 3.20)$ & \\
\hline \multicolumn{4}{|l|}{ Smoking } \\
\hline Yes (n=99) & $53(\% 52,50)$ & $46(\% 48.40)$ & \multirow{2}{*}{$0.570^{\mathrm{e}}$} \\
\hline No $(n=97)$ & $48(\% 47,50)$ & $49(\% 51.60)$ & \\
\hline Marital Status & & & \\
\hline
\end{tabular}




\begin{tabular}{|l|l|l|c|}
\hline Single $(n=47)$ & $28(\% 27,70)$ & $19(\% 20)$ & $0.206^{\mathrm{e}}$ \\
\cline { 1 - 3 } Married $(n=149)$ & $73(\% 72,30)$ & $76(\% 80)$ & $0.913^{\mathrm{a}}$ \\
\hline STAI-I & $36(20: 59)$ & $38(20: 73)$ & $0.202^{\mathrm{c}}$ \\
\hline STAI-II & $43,51 \pm 7,45$ & $44.93 \pm 7.97$ & $0.603^{\mathrm{a}}$ \\
\hline SAS & $22(10: 45)$ & $20(10: 45)$ & $0.292^{\mathrm{a}}$ \\
\hline HL-EU-Q16 & $19.79(9.38: 35.42)$ & $19.79(0: 34.38)$ & 0 \\
\hline
\end{tabular}

Data are expressed as median (minimum: maximum), mean \pm sd deviation, and $n \%$.

a: Mann Whitney $U$ test, $c$ : Independent two-sample t test, e: Chi-square test

STAI-I: State anxiety inventory, STAI-II: Trait anxiety inventroy, SAS:Swallowing anxiety scale

Although there was no significant relationship between the duration of endoscopy and age, it was determined that it did not differ according to gender, economic status, education level, smoking status and marital status $(p>0.05)$. Again, no significant correlation was found between the total scores obtained from the STAI, SAS, and HL-EU-Q16 scales and the duration of endoscopy ( $p>0.05)$. In addition to the analyzes given in Table-6, it was investigated whether the duration of endoscopy differed between patient groups with and without psychiatric disease. The median endoscopy time was 150 seconds (minimum: $120 \mathrm{sec}$ - maximum: $225 \mathrm{sec})$ in patients with psychiatric disease $(n=50)$ and 140 seconds (minimum: $110 \mathrm{sec}$ - maximum: 240 sec.) in the patient group without psychiatric disease. It was determined that the duration of endoscopy was longer in the patient group with psychiatric disease $(p=0.021)$ (Table 3).

Table3. The relationship of Gastroscopy time with socio-demographic data and the scales used

\begin{tabular}{|c|c|}
\hline$n=196$ & Gastroscopy Time \\
\hline \multicolumn{2}{|l|}{ Age (years) } \\
\hline$r_{s}$ & 0.09 \\
\hline$p$-value & 0.231 \\
\hline \multicolumn{2}{|l|}{ Gender } \\
\hline Female (n=119) & $146.55 \pm 20.99$ \\
\hline Male $(n=77)$ & $147.27 \pm 21.60$ \\
\hline$p$-value ${ }^{a}$ & 0.971 \\
\hline \multicolumn{2}{|l|}{ Occupation } \\
\hline Student $(n=13)$ & $150(130: 184)$ \\
\hline Officer $(n=10)$ & $140(124: 214)$ \\
\hline Worker $(n=65)$ & $140(120: 225)$ \\
\hline Retired (n=28) & $147,50(120: 140)$ \\
\hline Housewife $(n=80)$ & $144,50(110: 240)$ \\
\hline$p$-value $e^{b}$ & 0.900 \\
\hline
\end{tabular}




\begin{tabular}{|c|c|}
\hline Education & \\
\hline Primary $(n=86)$ & $146(110: 240)$ \\
\hline Secondary $(n=28)$ & $140(115: 190)$ \\
\hline High School $(n=48)$ & $138(115: 214)$ \\
\hline University (2 years) ( $n=15)$ & $142(132: 170)$ \\
\hline University (>2 years) $(n=19)$ & $148(130: 184)$ \\
\hline$p$-value $e^{b}$ & 0.128 \\
\hline Smoking & \\
\hline Yes $(n=99)$ & $145(115: 240)$ \\
\hline No $(n=97)$ & $140(110: 240)$ \\
\hline$p$-value ${ }^{a}$ & 0.457 \\
\hline Marital Status & \\
\hline Single $(n=47)$ & $142(110: 240)$ \\
\hline Married ( $n=149)$ & $144(115: 240)$ \\
\hline$p$-value ${ }^{a}$ & 0.807 \\
\hline STAI-I & \\
\hline$r_{s}$ & 0.09 \\
\hline$p$-value & 0.225 \\
\hline STAI-II & \\
\hline$r_{s}$ & 0 \\
\hline$p$-value & 0.950 \\
\hline SAS & \\
\hline$r_{s}$ & -0.01 \\
\hline$p$-value & 0.916 \\
\hline HL-EU-Q16 & \\
\hline$r_{s}$ & -0.06 \\
\hline$p$-value & 0.389 \\
\hline
\end{tabular}

Data are expressed as median (minimum: maximum) and mean $\pm s d$ deviation.

a: Mann Whitney U test, b: Kruskal Wallis test, rs: Spearman correlation coefficient

There is a significant relationship between the scores obtained from the QLS and the state anxiety scale
( $r s=0.22, p=0.002$ ). There was also a significant relationship between the swallowing anxiety scale and the scores obtained from the trait anxiety scale $(r s=0.37, p<0.001)$ (Table 4). 
Table4. The relationship between STAI and SAS

\begin{tabular}{|r|c|c|}
\hline \multicolumn{1}{|c|}{$\mathbf{n}=\mathbf{1 9 6}$} & STAI-I & STAI-II \\
\hline \multicolumn{1}{|c|}{ SAS } & & \\
\hline$r_{s}$ & 0.22 & 0.37 \\
\hline$p$-value & $\mathbf{0 . 0 0 2}$ & $<0.001$ \\
\hline
\end{tabular}

rs: Spearman correlation coefficient,

STAI-I: State Anxiety Inventory, STAI-II: Trait Anxiety Inventroy, SAS: Swallowing anxiety scale

(Sensitivity $=65.22 \%$, Specificity $=53.54 \%$, AUC $=$

ROC (Receiver operator characteristic curve) analysis was performed to predict the patient's presence of anxiety and whether this anxiety was continuous or not, according to the STAI-I and STAI-II scales. If the total score to be obtained from the SAS is $>19$
0.61 , and $\mathrm{p}=0.008)$, the patient will have anxiety (Figure1) and the total score will be $>22$ ( in the case of Sensitivity $=55.79 \%$, Specificity $=76.24 \%$, $\mathrm{AUC}=0.70$ and $\mathrm{p}<0.001$ ), it was predicted that the continuity of this anxiety could be mentioned (Figure2).

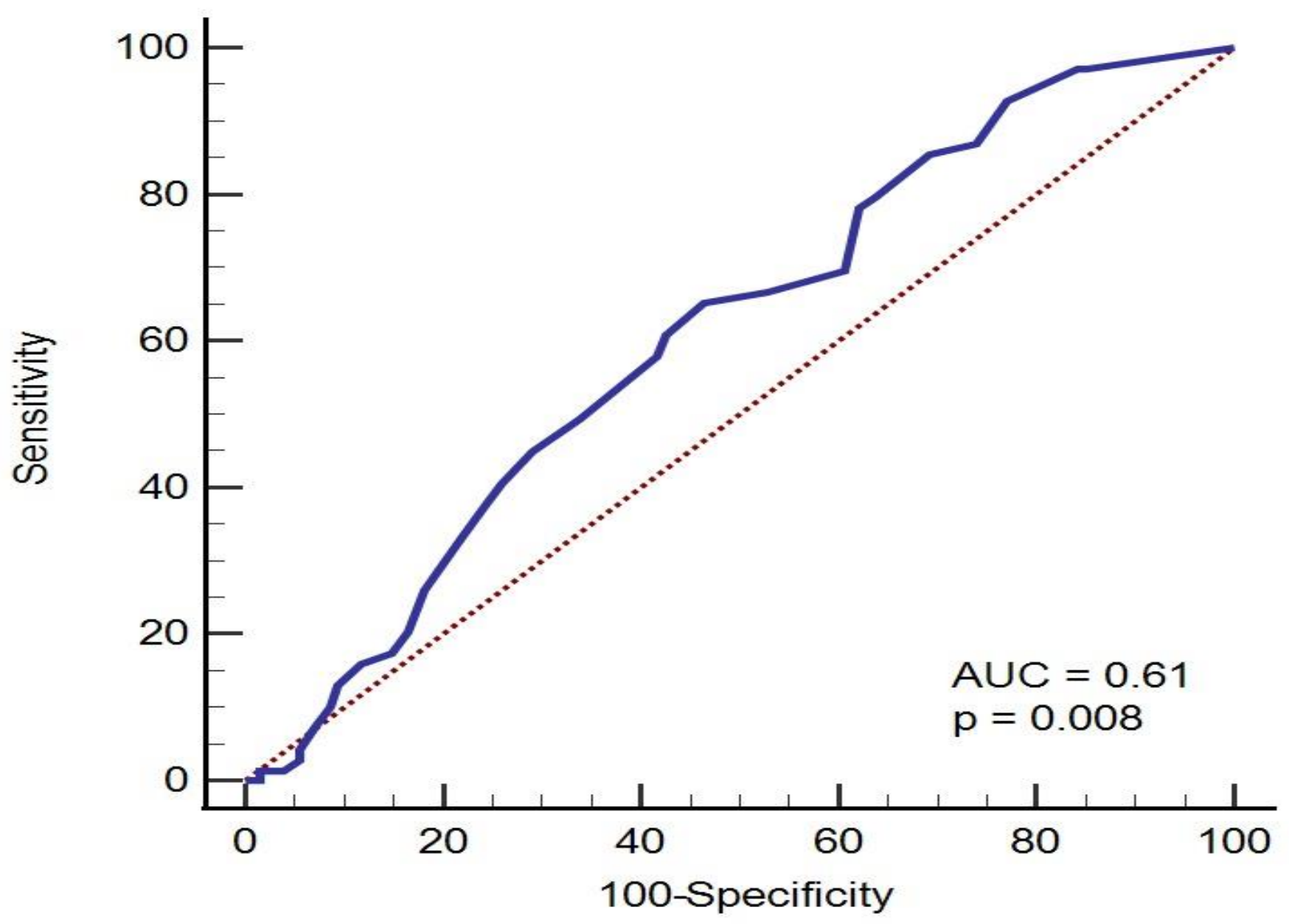

Figure1. ROC analysis to determine the presence of anxiety in the patient. The area under the curve for the swallowing anxiety scale was calculated as AUC $=0.61$ (Cut-off point $>19$, Sensitivity $=65.22 \%$ and Specificity $=53.54 \%$ ). 


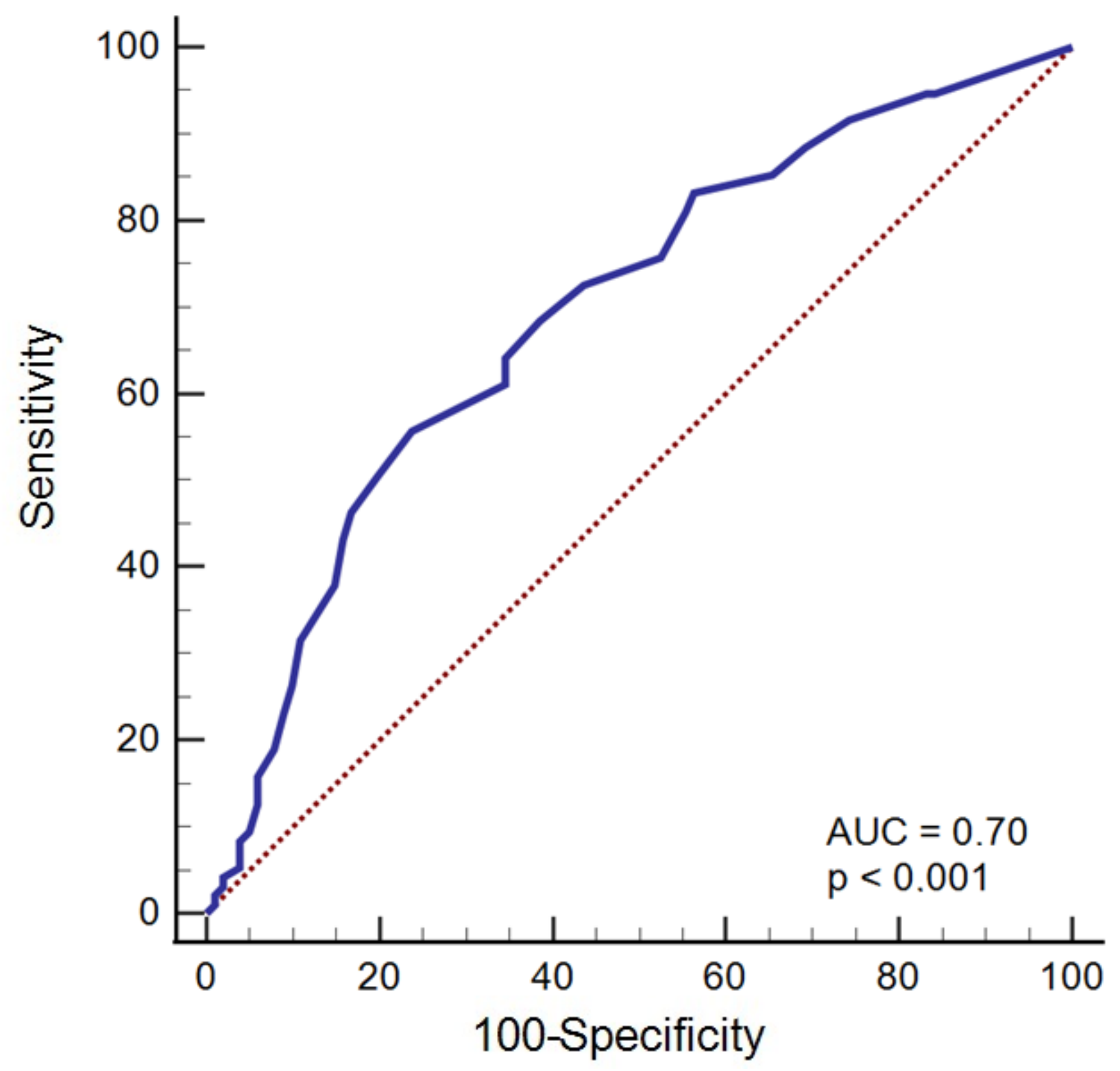

Figure2. ROC analysis to determine the persistence of anxiety in the patient. The area under the curve for the swallowing anxiety scale was calculated as AUC $=0.70$ (Cut-off point $>22$, Sensitivity $=55.79 \%$ and Specificity $=76.24 \%$ ).

\section{Discussion}

In the study, it was found that women who underwent endoscopy had higher levels of state and trait anxiety symptoms than men. As a result of epidemiological studies, it was stated that these anxiety disorders are 1.7 times more common in women than men, and similarly, twelve-month-old anxiety disorders are 1.8 times more common in women than in men (22). It has been reported that somatic-based complaints are more common in women $(23,24)$. Therefore, it can be said that anxiety and swallowing apricot symptoms are 
more common among women than men in dyspepsia patients, similar to the normal population.

In the study, it was determined that the rate of patients with undergraduate education was higher in the local anesthesia group, and the probability of choosing local anesthesia was 4-6 times higher than the other education groups. Education is one of the most important factors that determine the decisions people make on their lives. In educated individuals, the process of reviewing options and decision-making functions differently than those with low education (25). For this reason, it can be said that educated people who are informed by physicians before endoscopy have a high level of training to benefit from options that can be easier and are more conscious. In other words, it can be said that people with low educational status demand the completion of the procedure by being put to sleep more often due to health concerns or fear of endoscopy.

In the study, it was found that the duration of endoscopy was longer in people with mental disorders than in people without mental disorders. It has been found that psychopathological features can be seen at a more severe level in people with severe dyspeptic complaints, and symptoms such as stress, somatization, depression and phobia are associated with severe dyspeptic complaints (26). It has been found that dyspeptic complaints are more common in individuals with severe complaints related to personality and psychiatric disorders, and the severity of dyspeptic symptoms is associated with the presence of depression and somatization symptoms (5). In this study, longer duration of endoscopy in people with mental disorders was associated with more severe physical and mental complaints in these individuals.

In the study, it was found that there was a significant positive relationship between swallowing anxiety symptoms and state anxiety symptoms and trait anxiety symptoms. Budak et al. (2018) found that state and trait anxiety symptoms were highly positively correlated with swallowing anxiety symptoms in patients diagnosed with panic disorder, and that swallowing anxiety symptoms in individuals could be explained by trait anxiety symptoms. It has been found that somatic complaints and dyspeptic symptoms are common in patients with functional dysphagia, and the symptoms of dysphagia seen in these individuals are associated with anxiety symptoms (27). Swallowing apricot is a concept that has just begun to be studied in the literature and was developed to measure somatic and psychological symptoms of dysphagia. As a result of this study, it can be said that the symptoms of swallowing anxiety seen in dyspeptic patients may be related to the symptoms of state and trait anxiety.

Studies in the literature focused on general anxiety symptoms, often among psychogenic factors, in the quality of endoscopy applied to patients with dyspepsia. In these studies, it was stated that high anxiety symptoms in individuals diagnosed with dyspepsia may cause different health problems during and after the application, and therefore, anxiety symptoms negatively affect the healthy performance of endoscopy $(9,17,18)$. In this study, the effect of swallowing anxiety, which is a newly defined concept, on the results of endoscopy in dyspeptic patients was investigated. Although endoscopy is a medical procedure performed orally and closely related to the swallowing reflex, it was found that swallowing anxiety did not have a significant and significant effect on endoscopy in these patients, and anxiety symptoms in these patients may be related to swallowing apricots. Therefore, investigating the effect of swallowing apricot on the process before and after endoscopic applications in different and larger populations may contribute to the literature. 
It can be said that getting a score of 19 or higher on the SAS reaches a serious level of psychological problems related to swallowing. Psychologically based swallowing problems seen in people in SAS are defined as worrying when swallowing something, difficulty in swallowing solid food, difficulty in breathing when swallowing, throat congestion when angry, feeling of something pressing on the throat, fear of choking while eating something, and cessation of eating due to swallowing problems. In addition, it has been stated that psychological swallowing problems are common in individuals with dyspeptic complaints, that endoscopy may cause a traumatic swallowing experience, and swallowing phobia may occur in individuals accordingly $(16,28)$. Dyspepsia is a common health problem, and endoscopy applications are frequently used in these people. Therefore, it is beneficial for public health to choose the right endoscopy method in these individuals and to control the effects of factors that may adversely affect the endoscopy process. It should be kept in mind that state and trait anxiety is high in patients presenting with dyspeptic complaints, in addition, swallowing anxiety symptoms are common in these individuals and these symptoms may adversely affect the endoscopy process. Especially in dyspeptic patients, SAS is an appropriate measurement tool in order to determine swallowing problems of psychological origin, and it may be beneficial for patients' mental health to plan anti-anxiety information activities before endoscopy with dyspepsia patients who score 19 or higher in SAS.

In conclusion, state and trait anxiety symptoms and swallowing anxiety symptoms are common in patients presenting with dyspeptic complaints. In dyspeptic patients, SAS is an appropriate measurement tool in order to determine swallowing problems of psychological origin. It may be beneficial for their mental health to provide anti-anxiety information before endoscopy to people with a score of 19 or higher on SAS. The fact that health literacy results are not associated with anxiety tests is a valuable finding. It suggests that while making the accurate health decisions, individuals exhibit an anxiety-free behavior.

\section{CONFLICT OF INTEREST}

The authors declare that there is no conflict of interest. 


\section{References}

1. Çalışkan HM, Çelik B, Ersoy S. Dispeptik yakınmalarla acil servise müracat eden hastalarda etiyolojik değerlendirme. Akademik Gastroenteroloji Dergisi 2020;19;41-48.

2. Jones R, Lydeard S. Prevalence of symptoms of dyspepsia in the community. $\mathrm{Br}$ Med J 1989;298:30-32.

3. Ford AC, Marwaha A, Sood R, Moayyedi P. Global prevalence of and risk factors for uninvestigated dyspepsia: a metaanalysis. Gut 2015;64:1049-1057.

4. Oustamanolakis P Tack J. Dyspepsia: organic versus functional. J Clin Gastroenterol 2012;46:175-190.

5. Mujakovic S, De Wit NJ, Van Marrewijk CJ, Fransen GAJ, Laheij RJF, Muris JW Numans ME. Psychopathology is associated with dyspeptic symptom severity in primary care patients with a new episode of dyspepsia. Aliment Pharmacol Ther 2009;29;80-588.

6. Filipović BF, Randjelovic $\mathrm{T}$, Ille $\mathrm{T}$, Markovic O, Milovanović B, Kovacevic N, Filipović BR. Anxiety personality traits and quality of life in functional dyspepsia suffering patients. Eur J Intern Med 2013;24:83-86

7. Quadri A, Vakil N. Health related anxiety and the effect of open access endoscopy in US patients with dyspepsia. Aliment Pharmacol Ther 2003;17:835-840

8. Pontone S, Tonda M, Brighi M, Florio M, Pironi D, Pontone P. Does anxiety or waiting time influence patients' tolerance of upper endoscopy? Saudi J Gastroenterol 2015;21:111.

9. Yang M, Lu LL, Zhao M, Liu J, Li QL, Li Q, Yuan JQ. Associations of anxiety with discomfort and tolerance in Chinese patients undergoing esophagogastroduodenoscopy. PloS one 2019; 14:e0212180.

10. Maurer J, Hipp M, Schäfer C, Kölbl O. Dysphagia. Radiation Therapy and Oncology 2011;187: 744-749.
11. Boersma CC, Borowitz SM. Odynophagia. Clinical pediatrics 2007;46:556559.

12. Levent E, Sarıman N, Soylu AC, Yurtlu S, Tezcan AE. Evaluation of patients with globus hysterecus by polysomnography. Maltepe Medical Journal 2009;1:11-20

13. Baijens LW, Koetsenruijter K, Pilz W. Diagnosis and treatment of phagophobia: a review. Dysphagia 2013;28:260-270

14. Budak E, Taymur I, Önen S, Kanat BB, Akdeniz Ö, Demirci H. Symptoms of swallowing anxiety in panic disorder patients and associated psychopathologic factors. Eat Weight Disord 2018;23:487-497.

15. Conchillo JM, Selimah M, Bredenoord AJ, Samsom M, Smout AJPM. Air swallowing belching acid and nonacid reflux in patients with functional dyspepsia. Aliment Pharmacol Ther 2007;25: 965-971.

16. Kim Y, Kim J, Cohen A, Backus M, Arnovitz M, Rice T, Coffey BJ. Medication nonadherence secondary to choking phobia phagophobia in an adolescent with significant trauma history: addressing the issue of mental contamination.J Child Adolesc Psychopharmacol 2017;27:667-672.

17. E Mulcahy P, Kelly MR, Banks P, Connor SE, Patchet MJG. Farthing PD, Fairclough PJ, Kumar H. Factors associated with tolerance to and discomfort with unsedated diagnostic gastroscopy. Scand J Gastroenterol 2001;36:1352-1357.

18. Mahajan L, Wyllie R, Steffen R, Kay M, Kitaoka G, Dettorre J, McCue K. The effects of a psychological preparation program on anxiety in children and adolescents undergoing gastrointestinal endoscopy. J Pediatr Gastroenterol Nutr 1998;27:161-165.

19. Spielberger CD, Gorsuch RL, Lushene RE. State-trait anxiety inventory self-evaluation questionnaire. Consulting Psychololgists Press 1970.

20. Öner N, Le Compte A. Durumluk ve Sürekli Kaygı Envanteri El Kitabı Boğaziçi Üniversitesi Yayınları, İstanbul 1983.

21. Emiral GO, Aygar H, Isiktekin B, Göktas S, Dagtekin G, Arslantas D, Unsal A. Health literacy scale-European union-Q16: a validity and reliability study in turkey. Int Res J Med Sci 2018;6:1-7. 
22. McLean CP, Asnaani A, Litz BT, Hofmann SG. Gender differences in anxiety disorders: prevalence course of illness comorbidity and burden of illness J Psychiatr Res 2011;45:1027-1035.

23. Sheikh JI, Leskin GA, Klein DF. Gender differences in panic disorder: findings from the National Comorbidity Survey. Am J Psychiatry 2002;159:55-58.

24. Ballering AV, Bonvanie IJ, Hartman TCO, Monden R, Rosmalen JG. Gender and sex independently associate with common somatic symptoms and lifetime prevalence of chronic disease. Soc Sci Med 2020;253:112968.

25. Banks J, Carvalho LS, Perez-Arce F. Education decision making and economic rationality. Review of Economics and Statistics 2019;101:428-441.

26. Hsu YC, Liou JM, Liao SC, Yang TH, Wu HT, Hsu WL, Wu M S. Psychopathology and personality trait in subgroups of functional dyspepsia based on Rome III criteria. Am J Gastroenterol 2009;104:25342542.

27. Haug TT, Wilhelmsen I, Ursin H, Berstad A. What are the real problems for patients with functional dyspepsia? Scand J Gastroenterol 1995;30:97-100.

28. Azzam NA, Almadi MA, Alamar HH, Almalki LA, Alrashedi RN, Alghamdi RS, Al-Hamoudi W. Performance of American Society for Gastrointestinal Endoscopy guidelines for dyspepsia in Saudi population: prospective observational study. World J Gastroenterol 2015;21:637. 